\title{
ESTRATÉGIAS UTILIZADAS PARA O ENSINO DE URGÊNCIA/ EMERGÊNCIA EM UM CURSO DE GRADUAÇÃO EM ENFERMAGEM ${ }^{1}$
}

\author{
Luiz Alves Morais Filho², Jussara Gue Martini³, Daniele Delacanal Lazzari , Mara Ambrosina Vargaš , Vânia \\ Marli Schubert Backes ${ }^{6}$, Glaucea Maciel de Farias ${ }^{7}$
}

\begin{abstract}
${ }^{1}$ Artigo extraído da tese - Ensino do cuidado profissional em urgência/emergência em um curso de graduação em enfermagem do Rio Grande do Norte, apresentada ao Programa de Pós-Graduação em Enfermagem (PEN) da Universidade Federal de Santa Catarina (UFSC), em 2015.

${ }^{2}$ Doutor em Enfermagem. Professor do Departamento de Enfermagem da Faculdade de Ciência da Saúde do Trairi, Universidade Federal do Rio Grande do Norte (UFRN). Natal, Rio Grande do Norte, Brasil. E-mail: moraisfilho2004@hotmail.com

${ }^{3}$ Doutora em Educação. Professora do Departamento de Enfermagem e do PEN/UFSC. Florianópolis, Santa Catarina, Brasil. E-mail: jussarague@gmail.com

${ }^{4}$ Doutora em Enfermagem. Professora do Departamento de Enfermagem da UFSC. Florianópolis, Santa Catarina, Brasil E-mail: danielelazza@gmail.com

${ }^{5}$ Doutora em Enfermagem. Professora do Departamento de Enfermagem e do PEN/UFSC. Florianópolis, Santa Catarina, Brasil. E-mail: maraav@terra.com.br

${ }^{6}$ Doutora em Enfermagem. Professora do Departamento de Enfermagem e do PEN/UFSC. Florianópolis, Santa Catarina, Brasil. E-mail: vania.backes@ufsc.br

${ }^{7}$ Doutora em Enfermagem. Professora do Departamento de Enfermagem da UFRN. Natal, Rio Grande do Norte, Brasil. E-mail: glauceamaciel@gmail.com
\end{abstract}

\section{RESUMO}

Objetivo: identificar estratégias de ensino e avaliação utilizadas para os conteúdos relativos à urgência e emergência em um curso de graduação de emfermagem.

Método: estudo de caso único, analítico, com abordagem qualitativa, que se constituiu em um curso de graduação em enfermagem do estado do Rio Grande do Norte, Brasil. A coleta de dados ocorreu de agosto a dezembro de 2014. Entrevistou-se 13 professores, observaram-se 18 aulas práticas de laboratório e analisaram-se 13 planos de disciplinas, além do Projeto Pedagógico do Curso. A análise dos dados foi ancorada na estrutura do estudo de caso e na Análise de Conteúdo.

Resultados: a partir da análise dos dados, emergiram duas categorias: Estratégias utilizadas nas aulas teóricas e práticas em laboratório e serviços e Avaliação de alunos no ensino de urgência e emergência. Foi possível identificar que, apesar da intencionalidade, ainda estava presente a concepção de transmissão de conteúdos, além da dificuldade para sua seleção. A avaliação dos alunos foi igualmente uma dificuldade, não apenas para a construção de instrumentos, mas também, de como o professor desenvolveu esse processo.

Conclusão: há múltiplas possibilidades a serem exploradas para a qualificação do ensino na enfermagem, desde a adoção de novas posturas condizentes com as políticas educacionais e suas intenções, até a utilização das mais variadas formas de ensinar e avaliar.

DESCRITORES: Ensino. Avaliação. Currículo. Emergência. Prática profissional. Educação em enfermagem.

\section{STRATEGIES USED FOR TEACHING URGENCY/EMERGENCY IN A NURSING UNDERGRADUATE COURSE}

\begin{abstract}
Objective: to identify teaching and assessment strategies used for the contents concerning the urgency and emergency in an undergraduate nursing course.

Method: single case study with a qualitative approach, which is part of an undergraduate nursing course in the state of Rio Grande do Norte, Brazil. The data collection was carried out from August to December 2014. We interviewed 13 professors, observed 18 practical laboratory classes, and analyzed 13 course plans, in addition to the Pedagogical Project of the Course. The data analysis was anchored in the case study structure and Content Analysis.

Results: from the analysis of the data, two categories have emerged: Strategies used in theoretical and practical classes in laboratory and services and Assessment of students in the teaching of urgency and emergency. It was possible to identify that, despite the intentionality, the concept of content transmission was still present, besides the difficulty for its selection. The assessment of the students was also a difficulty, not only for the construction of the instruments, but also due to the way that the teacher has developed this process.

Conclusion: there are many possibilities to be explored for the qualification of teaching in nursing, from the adoption of new positions consistent with the educational policies and their intentions, to the use of the most varied ways of teaching and evaluating.

DESCRIPTORS: Teaching. Assessment. Curriculum. Emergency. Professional practice. Education in nursing.
\end{abstract}




\section{ESTRATEGIAS UTILIZADAS PARA LA ENSEÑANZA DE LA URGENCIAY EMERGENCIA EN UN CURSO DE GRADUACIÓN EN ENFERMERÍA}

\section{RESUMEN}

Objetivo: identificar estrategias de enseñanza y evaluación utilizadas para los contenidos relativos a la urgencia y emergencia.

Método: estudio de caso único, analítico y con abordaje cualitativo que se constituyó en un curso de graduación en enfermería del Estado de Rio Grande do Norte. La recolección de datos se realizó de Agosto a Diciembre del 2014. Se entrevistaron 13 profesores, se observaron 18 clases prácticas de laboratorio y se analizaron 13 planes de materias, además del Proyecto Pedagógico del Curso. El análisis de los datos se fundamentó en la estructura del estudio de caso y en el Análisis del Contenido.

Resultados: a partir del análisis de los datos emergieron dos categorías: Estrategias utilizadas en las clases teóricas y prácticas en laboratorio y servicios, y Evaluación de alumnos en la enseñanza de urgencia y emergencia. Fue posible identificar que, a pesar de la intencionalidad, todavía estaba presente la concepción de transmisión de contenidos además de la dificultad para su selección. La evaluación de los alumnos fue igualmente una dificultad no solo para la construcción de instrumentos sino también sobre cómo el profesor desarrolló ese proceso.

Conclusión: hay múltiples posibilidades para ser explotadas sobre la cualificación de la enseñanza en la enfermería, desde la adopción de nuevas posturas condecentes con las políticas educacionales y sus intenciones hasta la utilización de las más variadas formas de enseñanza y evaluación.

DESCRIPTORES: Enseñanza. Evaluación. Currículo. Emergencia. Práctica profesional. Educación en enfermería.

\section{INTRODUÇÃO}

A formação do enfermeiro crítico, reflexivo, criativo e com competências técnicas e políticas para o exercício profissional, em consonância com as Diretrizes Curriculares Nacionais (DCN) do curso de graduação em Enfermagem, perpassa, necessariamente, pela adoção de novas estratégias para ensinar, bem como, pelo aprimoramento das já existentes, visando ao favorecimento das diferentes formas de apropriação dos conteúdos. ${ }^{1-2} \mathrm{~A}$ utilização de metodologias ativas e o protagonismo dos estudantes corresponsáveis por sua formação apontam, atualmente, para a revisão de estratégias que possibilitem novas e variadas experiências de aprendizagem.

As tendências pedagógicas da graduação em enfermagem apontam para o desejo de rompimento com o modelo cartesiano no processo ensino-aprendizagem. ${ }^{3}$ É notória, para os cursos de graduação da saúde, que a formação profissional permanece pautada na utilização de metodologias tradicionais, fortemente influenciadas pela compartimentalização dos currículos, resultando em fragmentação de conteúdos e, consequentemente, do conhecimento.

Nesta realidade, a adoção de posturas apenas transmissivas pelo professor atribuiu ao aluno o papel de expectador ou receptor de informações. Isto posto, ao se refletir sobre as necessidades atuais com relação ao perfil profissional desejado para os trabalhadores da saúde, nota-se que a eficiência técnica com conhecimento especializado e formação crítica, reflexiva e política demandam modificações não apenas nas posturas dos professores, mas também, na forma como se tem percebido o aluno e o ensino. ${ }^{4}$

A partir da organização da enfermagem, enquanto ciência e profissão, o ensino dos conhecimentos que lhe são próprios tem igualmente evoluído, num contexto em que é necessário pensar não apenas as relações em sala de aula, e sim, em outros espaços dialógicos, tais como os campos de prática. Nestes últimos, mais intensamente, surge a necessidade de integrar saberes de múltiplas áreas coordenados com o desenvolvimento de habilidades, principalmente aquelas relativas ao raciocínio clínico e ao fazer. É particularmente importante observar esta realidade em áreas em que o conhecimento especializado orienta a aquisição de habilidades manuais, na mesma medida em que exige conhecimento das políticas públicas, além daquele da especialidade. ${ }^{5}$

A atuação do enfermeiro em serviços de urgência e emergência demanda variados conhecimentos, indispensáveis à assistência de pacientes com necessidades complexas. As tecnologias presentes, a necessidade permanente de aprimoramento científico e a humanização dos cuidados configuram particularidades às ações dos enfermeiros. ${ }^{6}$ Com a implantação do Sistema Único de Saúde surgiu a necessidade de direcionar a formação dos profissionais da saúde a fim de atuar numa rede de serviços regionalizada e hierarquizada de cuidados integrais às urgências, por meio da Política Nacional de Atenção às Urgências e Emergências. ${ }^{7}$

Coadunando o perfil pretendido de profissionais pelas DCN as políticas públicas, à necessidade de conhecimento especializado e o ensino na enfermagem, torna-se essencial a adoção de metodologias de ensino que não apenas deem conta de propiciar compreensão sobre o cenário de saúde atual, como também permitam formação crítica, criativa e reflexiva. Há, portanto, demanda para a utilização de estratégias de ensino não individualizantes, além da percepção de que se apropriar das características individuais dos estudantes fortalece a aprendizagem. ${ }^{8-9}$ 
Desta forma, questiona-se: quais as estratégias de ensino e avaliação utilizadas para os conteúdos de urgência e emergência na graduação em enfermagem? Para tanto, objetivou-se identificar as estratégias de ensino e avaliação relativas à urgência e emergência em um curso de graduação em enfermagem.

\section{MÉTODO}

Estudo de caso único, analítico e exploratório, com abordagem qualitativa. $\mathrm{O}$ caso selecionado foi um curso de graduação em enfermagem de uma instituição pública da região Nordeste do Brasil. Este curso foi escolhido por pertencer a uma universidade pública, sendo um dos mais antigos do estado do Rio Grande do Norte e ter grande representatividade em termos de número de alunos formados. Sua organização se dá em semestres, agrupados em nove eixos temáticos/fases, e as atividades de ensino desenvolvidas são organizadas por meio de disciplinas integradas e atividades de formação de natureza obrigatória ou optativa; disciplinas e atividades complementares de natureza optativa; estágios integrados ao longo do curso; e, dos estágios supervisionados obrigatórios.

O foco se centrou no ensino de conteúdos de urgência e emergência em enfermagem nas disciplinas referentes às Ciências da Enfermagem, tanto aquelas específicas ou responsáveis pelo ensino de conteúdos de urgência e emergência, como naquelas que abordam essa temática em sua área. Foram analisados o Projeto Pedagógico do Curso (PPC) e os planos de ensino das disciplinas; foram observadas aulas práticas nos laboratórios de habilidades/ simulação; e entrevistaram-se os professores. Após contato inicial e aprovação da coordenação do curso e contato com os professores via e-mail, os planos foram fornecidos pelos docentes. A escolha destes para a entrevista se deu a partir da análise dos planos das disciplinas e da relação da disciplina que ministravam com os conteúdos relativos a urgência e emergência. As entrevistas tiveram tempo de duração de 40 a 50 minutos e ocorreram nas salas dos professores, ou em sala de aula, de forma privativa, sendo gravadas em áudio e o registro das observações por meio de diário de campo. Para a realização das entrevistas, construiu-se roteiro semiestruturado.

Adotaram-se como critérios de inclusão: ser professor de disciplinas específicas de urgência e emergência ou disciplinas que abordassem conteúdos relativos en qualquer etapa do ciclo de vida; aulas práticas em laboratório que desenvolvessem ações pertinentes à urgência e emergência; planos de ensino de disciplinas específicas sobre o conteúdo de urgência e emergência ou que tratassem, em qualquer fase do curso, de temas relativos a esta especialidade.

Evidenciou-se que o ensino de urgência e emergência acontece de forma transversal ao longo de três fases: quinta, sexta e sétima. Na quinta fase, a disciplina denominada Atenção I é o componente curricular em que ocorre o primeiro contato com a área de urgência e emergência por meio de alguns tópicos. Nessa fase, o conteúdo sobre suporte básico de vida é ensinado por meio de aulas teóricas e práticas em laboratório.

Na sexta fase, Atenção II é considerada a disciplina responsável pelo ensino de urgência e emergência, mas não exclusivamente. A urgência e emergência é ministrada conjuntamente com os conteúdos relativos ao paciente crítico em Unidade de Terapia Intensiva (UTI). Nesta etapa, o estudante, além das aulas teóricas e práticas em laboratório, desenvolve atividades em serviços tais, como as Unidades de Pronto Atendimento (UPAs).

Na sétima fase, a disciplina Atenção III, aborda a saúde materno e infantil nos três níveis de complexidade. Há conteúdos de urgência e emergência inseridos nas áreas da pediatria e obstetrícia. As aulas são de cunho teórico e práticas em laboratório e em serviço específico de emergência pediátrica. $\mathrm{Na}$ área da urgência e emergência obstétrica, as aulas são teóricas e práticas em laboratório (há atividades em sala de parto, alojamento conjunto, UTI materna e UTI neonatal, porém, são gerais para todos os tipos de cuidados, não apenas aos relativos à urgência $\mathrm{e}$ emergência).

Foram identificados 13 professores que ensinam os conteúdos de urgência e emergência (em disciplinas específicas da área ou não), sendo que todos aceitaram participar deste estudo, totalizando 208 minutos e 12 segundos de gravação. Realizaram-se observações em 18 aulas no laboratório de habilidades, totalizando 40 horas e dez minutos, com média de 2,2 horas por aula. Foram analisados 13 planos de disciplinas.

A análise dos dados foi ancorada na estrutura do estudo de caso, com leituras sucessivas do material, para realização das codificações e as categorizações. Para tal, utilizou-se a Análise de Conteúdo proposta por Bardin, ${ }^{10}$ composta por três fases: pré-análise; exploração do material; tratamento dos resultados e interpretação. Primeiramente, analizou-se o conteúdo das entrevistas. Posteriormente, examinaram-se os documentos e as observações 
registradas no diário de campo. Para auxiliar na organização dos dados, utilizou-se o software Atlas. $\mathrm{ti}^{\circledR}$ versão 7.5.4.

Após a codificação, os dados foram organizados em categorias. A pesquisa seguiu os princípios, normas e diretrizes éticas para pesquisas envolvendo seres humanos, em consonância com a Resolução n. 466, de 12 de dezembro de 2012, do Conselho Nacional de Saúde. O projeto foi aprovado pelo Comitê de Ética em Pesquisa da Universidade Federal do Rio Grande do Norte, com o Parecer do CEP n. 764.031, de 22 de agosto de 2014, CAAE: 31745514.5.0000.5568. Todos os participantes assinaram o Termo de Consentimento Livre e EsclarecidoO anonimato foi preservado pela identificação dos professores através da letra " $\mathrm{P}$ " seguida do número correspondente à ordem de realização da entrevista. As observações foram identificadas pela sigla "OBS" e número correspondente à ordem de leitura. Os planos das disciplinas foram identificados pelas letras "PD" e número de acordo com a ordem de análise.

\section{RESULTADOS}

Emergiram duas categorias de análise: Estratégias utilizadas nas aulas teóricas e práticas em laboratório e serviços; e, Avaliação de alunos no ensino de urgência e emergência.

\section{Estratégias utilizadas nas aulas teóricas e práticas em laboratório de habilidades e serviços}

Com relação às aulas teóricas, foram identificadas as escolhas pelas aulas expositivas dialogadas, seminários e discussão de textos/artigos científicos. Uma das disciplinas estava centrada na proposta pedagógica da Aprendizagem Baseada em Problemas

Consiste em aulas expositivas dialogadas, na leitura e discussão de publicações científicas baseadas em evidências. (P01)

As aulas são aulas teóricas, com o máximo de participação possível. Utilizamos a metodologia participativa em sala de aula, seminários, dinâmicas, e a aula expositiva propriamente dita. (P07)

As abordagens metodológicas também são evidenciadas nos planos de ensino Metodologia [...] centrada na proposta pedagógica da aprendizagem baseada em problemas, na qual os docentes posicionam o aluno frente a situações reais de tomadas de decisões e condutas de enfermagem. (PD05)

Metodologia [...] aula expositiva e dialogada; casos clínicos; apresentação de trabalhos científicos; atividades práticas. (PD09)

Foi possível observar que parte das aulas práticas estava centrada na figura do professor como executor de alguma técnica e alunos como observadores.

As apresentações teóricas e dramatizações/simulações práticas para a resolução de um caso clínico, por um grupo de seis alunos. Em cada aula havia um grupo responsável por resolver esse caso clínico referente à temática da aula. Normalmente, havia apenas uma demonstração prática durante a resolução do caso, não havia execução da prática pelo restante da turma. Após esse primeiro momento, o professor, ou um especialista convidado, fazia um fechamento da aula com uma discussão teórica do tema, retomando também o caso. (OBS01)

As aulas teóricas ocorrem em estações de práticas. É distribuída para os alunos a base teórica, os artigos científicos, os protocolos de atendimento assistenciais, bem como o que já é de conhecimento nacional e internacional, implantado na assistência pré-hospitalar. Durante a semana, os alunos estudam casos clínicos, fazem estações práticas e há discussão e debate em plenária. (P02)

Durante as observações, identificou-se que, em uma mesma aula, foram utilizadas mais de uma abordagem metodológica.

A metodologia utilizada na aula foi resolução do caso clínico por meio de simulação/dramatização pelos alunos; discussão durante as apresentações; aula expositiva dialogada pelo professor; vídeo sobre a temática. (OBS02)

Variamos as estratégias, mas o conteúdo é imenso. É complicado querer abordar a complexidade da Urgência/ Emergência em estágios pequenos ou aulas para turmas muito grandes. (P06)

Em relação às aulas no laboratório de habilidades, as metodologias foram variadas: aulas expositivas dialogadas e demonstração de equipamentos e de técnicas. Foram realizadas atividades para pequenos grupos de quatro a seis alunos, com a presença de dois professores e a utilização de dois manequins. Nesse momento, os professores fizeram revisão teórica com demonstração da técnica. Após essa fase, esses pequenos grupos foram subdivididos em grupo de dois a três alunos. Nesse momento, a prática era realizada em um manequim e acompanhada por um professor. Cada procedimento era repetido várias vezes. Em seguida, os estudantes recebiam um caso clínico para ser resolvido. (OBS03)

Quanto às aulas práticas é demonstrado todo o processo de suporte básico de atendimento. Para que todos tenham a noção do início ao fim do atendimento, conheçam o material, o equipamento, 
a sequência. Depois eles são subdivididos em pequenos grupos, aí sim, praticam nos manequins. (P10)

Os alunos fazem as compressões cardíacas, simulam o choque, pensam nas possíveis causas da parada cardiorrespiratória. (P03)

A aula de Suporte Básico de Vida era realizada com grupos de quatro a seis alunos. Toda segunda acontecia uma aula exclusiva para esses pequenos grupos. A aula era coordenada por duas professoras, eram utilizados dois a três manequins por aula. É importante ressaltar que eles já haviam participado de uma aula teórica sobre a temática com toda a turma. (OBS09)

Ao observar as aulas em laboratório, foi possível identificar a abordagem de ensino fragmentada, com os alunos executando parte da prática, isolada de todo o processo: $O$ suporte avançado de vida foi trabalho separadamente, em etapas. Houve demonstração dos professores e repetição pelos alunos. Mas não houve uma simulação em que os alunos pudessem realizar todo o processo. (OBS06)

Nas aulas que ocorreram nos serviços, a proposta era de o aluno vivenciar todo o processo de trabalho do enfermeiro. Eles observaram todos os casos que chegaram ao serviço, mas prestaram assistência direta aos pacientes já estabilizados. A assistência aos pacientes mais graves dependeu da situação e da avaliação do professor, se considerasse que o aluno possuía competência para tal. (OBS07)

Não é tão fácil, não temos como ministrar todo o conteúdo possível com o aprofundamento desejado. Os casos clínicos nos ajudam nisso, dá para trabalhar um apanhado de situações em apenas um caso, mas temos noção do quanto fatiamos o conteúdo até gerar melhor entendimento. Ainda é difícil, com razão, para os alunos raciocinarem clinicamente. (P05)

Temos a dificuldade do número de alunos, o serviço só aceita três alunos por professor na alta complexidade. Então, o aluno ele fica seis dias em uma única UPA, $e$ mais seis dias em uma UTI. Esse é todo o estágio deles. Tivemos que fazer assim, pois antes, o aluno ficava basicamente dois dias em cada setor. Então, não tinha um grande aprendizado. (P12)

A despeito das limitações, com relação ao número de alunos nos campos de prática e das estratégias adotadas pelos professores, os conteúdos relativos à urgência e emergência, por seu caráter de complexidade, consistem, por vezes, em conteúdos isolados ou desenvolvidos de maneira que dificulta o desenvolvimento de raciocínio clínico e reflexivo. A quantidade de conteúdo a ser trabalhada em um pequeno espaço de tempo em função da formação generalista pretendida, pode limitar o aprendizado.

\section{Avaliação de alunos no ensino de urgência e emergência}

Quanto à avaliação, todas as disciplinas utilizaram a prova escrita e dessas, uma avaliou habilidades práticas no laboratório. A avaliação da simulação foi pelo método Objective Structured Clinical Examination (OSCE), utilizada em uma disciplina. As participações em seminários e apresentações de casos clínicos também eram estratégias adotadas para compor a avaliação.

A avaliação do conteúdo teórico e prático é realizada por meio de prova escrita e prova prática. [...] Os alunos devem resolver alguns casos clínicos com procedimentos em situações simuladas dentro do laboratório de habilidades. (P01)

Uma avaliação teórica, um pré-teste, um pós-teste e uma avaliação em estações práticas pelo método OSCE. (P02)

Estudo de caso ao final do estágio, e também, um relato de experiência no formato de artigo sobre os dois campos de estágios, a UTI e a unidade de urgência e emergência. (P12)

E também eles devem, no final da vivência no serviço, construir uma proposta de intervenção. Então, eles identificam um problema e estudam sobre esse problema, identificam algumas soluções possiveis e constroem um projeto de intervenção. Que é repassado para a administração do hospital como um feedback. (P01)

Quanto às abordagens metodológicas das avaliações evidenciadas nos planos de ensino das disciplinas, destacou-se que todas as disciplinas propõem avaliações práticas em laboratório, entretanto, o OSCE proposto no plano "PD06" não foi percebido na prática.

A avaliação é processual e consiste em avaliações escritas, pesquisas bibliográficas, presença e participação em sala de aula, métodos de simulação (como a avaliação clínica objetiva estruturada - OSCE). (PD05)

Na observação das aulas/avaliações práticas, pôde-se identificar a estrutura do OSCE, assim como do checklist utilizado para avaliar os alunos:

As estações foram sobre várias temáticas. Para cada uma, havia um cenário em uma sala, que simulava a realidade do serviço ou de um contexto pré-hospitalar. Em cada estação havia orientações com o caso e a ação que o aluno deveria executar, e dois professores com um checklist para realizar a avaliação. Em duas estações havia "atores/pessoas idosas" simulando pacientes. Os alunos executavam a prática em dupla e tinham 6 minutos para cada estação. Após realizarem a assistência nas seis estações, os alunos ficaram aguardando em uma sala onde 
era realizado o debriefing/feedback. [...]

O checklist avaliava os seguintes aspectos: segurança da cena, uso de EPI, habilidades específicas sobre a temática, trabalho em equipe e avaliação global do aluno. As temáticas segurança da cena, uso de EPI, e trabalho em equipe eram avaliadas de forma transversal em todas as estações. (OBS17)

Quanto à abordagem metodológica, o PPC do curso, em coerência com o perfil que se deseja formar, propõe a utilização de metodologias ativas e problematizadoras, desenvolvidas em pequenos grupos e articulando teoria e prática, assim como a utilização de avaliação formativa.

[...] utilizando metodologias ativas e problematizadoras desenvolvidas em pequenos grupos articulando a teoria e a prática, sendo acompanhado de um processo de avaliação formativa. (PPC01)

$\mathrm{O}$ incentivo à utilização de diversas metodologias constava no PPC e foram muitos os instrumentos e estratégias de avaliação citados pelos professores e observados nas aulas e nos planos de ensino. Os formulários para avaliação estavam presentes, bem como a observação da atuação dos alunos. Não foram encontradas evidências de autoavaliação por parte dos alunos.

\section{DISCUSSÃO}

Em consonância com o que está proposto nas DCNs, e em outros países, estudos sobre educação em enfermagem têm sinalizado a necessidade de programar e avaliar estratégias de ensino que ajudem os alunos a desenvolver o pensamento crítico, tomada de decisões e competência comunicativa. ${ }^{11}$

Uma formação profissional que privilegie o aprender por meio do fazer; que integre teoria e prática em um ensino reflexivo, baseado no processo de conhecer-na-ação; reflexão-na-ação e reflexão sobre a reflexão-na-ação, cuja capacidade de refletir seja estimulada através da interação professor/aluno em situações práticas diversas. ${ }^{12}$ Enfermagem baseada em evidências, portfólio, aprendizagem baseada em problemas, simulação e os ambientes virtuais de aprendizagem, mapas conceituais, processo de enfermagem, estudos de caso, seminários, aulas dialogadas, debates, jogo e atividades lúdicas, entre outros, são estratégias possíveis para o ensino na enfermagem. ${ }^{11}$

Com relação às estratégias utilizadas nas aulas teórico-práticas em laboratório de habilidades e nos serviços, percebeu-se o descompasso entre a proposta formal do curso via PPC e a utilização dessas no cotidiano dos professores. A multiplicidade de estratégias passíveis de utilização não elimina a necessidade de que se modifiquem filosofias há muito arraigadas no ensino, em particular no ensino superior, por seu caráter ainda profissionalizante em algumas áreas, em que, tradicionalmente, o que importa ao professor é o domínio da especialidade. Neste sentido, o desenvolvimento do pensamento reflexivo é elemento chave, principalmente por parte dos professores. ${ }^{8,13}$ Os avanços ocorridos no sentido de pensar e propor novas formas de ensinar, num afastamento gradual de aulas exclusivamente expositivas, impõem o desafio de compreender e adotar essas novas estratégias, visando o desenvolvimento da consciência crítica, do raciocínio clínico, do pensar sobre fazer, atribuindo-lhe novos significados.

Se o anseio a partir das DCNs era de superação do modelo de ensino focado na transmissão de informações, com ênfase na verticalidade da relação professor/aluno por meio de metodologias ativas de aprendizagem ${ }^{14}$ sua solidez será percebida com a mudança paradigmática sobre a forma de conceber o ensino e perceber o aluno. As propostas dos professores participantes desta pesquisa para suas rotinas acadêmicas se centram ainda, fortemente, em estratégias, tais como as aulas teóricas expositivas e/ ou dialogadas, seminários, discussões com base em textos ou artigos, demonstração de equipamentos e técnicas. Embora sejam adotadas a aprendizagem baseada em problemas, dramatização, simulação, segue-se a lógica da necessidade de repetição de procedimentos, após observação do professor, com ensino seguindo abordagem fragmentada e execução de partes das técnicas inerentes à profissão por alguns dos alunos (tais como a observação do conteúdo relativo ao suporte avançado de vida, trabalhado em etapas).

Mesmo quando se propõe pensar o ensino na formação generalista, pelo viés da especialidade, tal como a urgência e emergência, torna-se imperativo, neste contexto, dar conta de reorientar o modelo assistencial, descentralizando-o da doença para um modelo que privilegie a produção social da saúde. Deste modo, a adoção de metodologias inovadoras implica em compreender e fomentar educação com base em processos críticos de ensino e aprendizagem. $\cdot{ }^{15}$ Conteúdos isolados ou ministrados de maneira que não favorecem o raciocínio crítico, reflexivo, como observados nesta pesquisa, ou mesmo a quantidade de conteúdos a ser trabalhada em um semestre merecem atenção por parte dos professores, não apenas apontando para a urgência na adoção de posturas críticas a partir de outras compreensões sobre como o aluno aprende. 
Para atuar como facilitador do processo de ensino e intermediar a produção do conhecimento, conhecer os estilos de aprendizagem e as singularidades dos alunos compõe uma das necessidades dos professores para o ensino além de uma perspectiva crítica. ${ }^{16-17}$

Há limites e contradições sentidas na esfera da ausência de formação para a docência entre os professores entrevistados, principalmente, no que compete à adoção de metodologias de maneira apenas instrumental, desconectada de uma postura cuja amplitude dê conta de utilizar as mais variadas estratégias, num contexto permanente de articulação com os pressupostos reflexivos, críticos e criativos, que acolham os limites do raciocínio clínico dos alunos. ${ }^{18}$ Este panorama é extensivo aos demais cursos da área da saúde, cujo domínio da especialidade diante da ausência de preparo pedagógico, ainda norteia a noção de quem é bom professor ou professor de referência.

$\mathrm{Na}$ área da urgência e emergência, a necessidade de ensinar, mesmo na lógica do profissional generalista, a atuação para assistência imediata, integrada ao conhecimento técnico e habilidade, mediada pelo amplo uso da tecnologia, ${ }^{19}$ é igualmente um desafio. No entanto, é importante demarcar a formação em enfermagem e a formação do enfermeiro emergencista, habilitado para trabalhar no campo de tratamento de urgência e emergência, uma vez que o ensino clínico em enfermagem demanda formação prática e teórica, com o desenvolvimento de competências de forma integrada. Não se deve, portanto, exigir dos graduandos o mesmo entendimento que se tem sobre as habilidades de raciocínio imprescindíveis ao enfermeiro emergencista.

Mediante a possibilidade de os alunos vivenciarem o processo de trabalho do enfermeiro em campo de prática, observou-se que a assistência a pacientes graves dependia da situação e da avaliação desta pelo professor, delegando aos alunos a assistência direta aos pacientes já estabilizados. Logo, se o professor considerasse que o aluno possuía competência para tal, o aluno assumia a assistência sob sua supervisão. As relações entre professores e alunos constituem parte fundamental no desenvolvimento das estratégias de ensino e o estabelecimento de relações de confiança é permeado por valores, comportamentos e afetos estabelecidos mediante o encontro pedagógico. ${ }^{20}$

Nessa perspectiva, as tendências ativas orientam, na lógica do estabelecimento de afetos, o protagonismo do estudante, correponsabilizando-o pelo próprio processo de formação e contribuindo para o processo dos colegas, estimulando a criticidade, reflexividade e criatividade.$^{15}$ Estudo ${ }^{21}$ que objetivou subsidiar transformações necessárias a um currículo de um curso de graduação em enfermagem, apontou que, no que tange à construção da autonomia do estudante, os docentes, participantes do estudo, reconheceram a existência de dificuldades em estabelecer limites de segurança para o paciente, quando o estudante inicia a prática assistencial. Outros estudos ${ }^{22-23}$ propõem, para além da diversificação de estratégias, a compreensão da metateoria curricular neossistêmica para o desenvolvimento da autonomia do estudante, com ensino significativo, contextualizado e globalizado.

Com relação à avaliação, a participação do aluno é de grande importância, inclusive para avaliar os modelos de ensino adotados pelos professores desta pesquisa e seus desempenhos ao ensinar. As inovações curriculares devem contemplar as avaliações e não apenas se limitarem aos conteúdos e estratégias para ensinar. Por mais que se viabilizem inúmeras estratégias de ensino, a avaliação dos alunos é parte do processo e deve merecer tanta atenção quanto à definição do que e como ensinar.

O processo avaliativo classificatório e excludente gera dados que possibilitam apenas avaliar a capacidade do aluno em reter informações. No entanto, no novo modelo, assumiria um caráter formativo e de diagnóstico do ensino aprendizagem, apontando dificuldades e facilitando intervenções pedagógicas, gerando dados que permitem avaliar o desenvolvimento das competências. ${ }^{21}$

A avaliação, deixando de ser elemento de poder, com aspectos classificatórios e seletivos, pode compor um meio para a existência de diálogo entre os envolvidos e estratégia de crescimento conjunto, tanto no âmbito profissional quanto pessoal. Como ação intencional do processo educativo, distancia-se da aprendizagem por meio da recepção/repetição que se aproxima do acúmulo de conhecimento sem reflexão sobre, marcante no ensino tradicional. Dessa forma, o desafio que se impõe para os professores desta pesquisa é tornar a avaliação uma etapa dinâmica, reflexiva, crítica e criativa. ${ }^{12}$

Apesar do estímulo à utilização de novas e variadas metodologias, além da necessidade de compreender o processo de ensino por meio de outros paradigmas, no que compete à avaliação dos alunos quase sempre se recorre às provas escritas ou avaliação de habilidades adquiridas, como apontando pelos participantes desta pesquisa. Embora o PPC do curso em tela oriente a utilização de metodologias ativas e avaliação formativa, esta se dá por meio de formulários, checklist e observação 
por parte dos professores, sem a possibilidade de autoavaliação dos alunos.

A avaliação aplicada de forma classificatória, por meio de provas e resultados de notas, pode-se constituir por vezes, num equívoco, uma vez que o desenvolvimento do processo de ensino aprendizagem se alicerça nas relações entre os sujeitos. Se percebida como método diagnóstico, pode afastar o professor do papel de disciplinador. ${ }^{23-24}$

As estratégias metodológicas precisam buscar não o acúmulo de conhecimentos, mas, o desenvolvimento de conhecimentos, habilidades e atitudes, inclusive se ater àquelas relacionadas ao cuidado das urgências e emergências, na lógica de uma formação generalista.

Apesar das limitações deste estudo, decorridas, principalmente, em função do método de pesquisa adotado, explorar as estratégias adotadas pelos professores fomentou a necessidade de revisão na forma como se percebe o ensino, para a compreensão mais ampla sobre o tema.

\section{CONCLUSÃO}

Embora tenha sido possível perceber a intencionalidade para diversificação de estratégias, expressa no PPC ou no depoimento dos professores, ainda está presente a concepção de transmissão de conteúdos. Aulas expositivas e o sistema observação/repetição, podem, dependendo da forma de condução, fortalecer o ensino instrumental, fragmentado, que pouco contribui para a formação crítico, criativa e reflexiva.

O tempo de formação para estruturar o profissional generalista contribui para a sensação de que os conteúdos trabalhados nunca são o suficiente ou que o aluno permanecerá com lacunas de conhecimento a serem preenchidas. Com relação à avaliação, esta parece ser, continuamente, o nó górdio dos processos relativos ao ensino-aprendizagem. As dificuldades consistem não apenas na construção de formulários, mas também, quais aspectos avaliar, quando avaliar e como o professor desenvolverá esse processo.

\section{REFERÊNCIAS}

1. Meira MDD, Kurcgant P. Competências de egressos graduados em enfermagem: avaliação de gestores empregadores. Rev Cienc Gerenc [Internet]. 2015 [cited 2016 Jan 23]; 19(30):60-4. Available from:http:/ / pgsskroton.com.br/seer/index.php/rcger/article/ view/3666/3140

2. Cotta RMM, Silva LS, Lopes LL, Gomes KO, Cotta FM, Lugarinho R, et al. Construção de portfólios coletivos em currículos tradicionais: uma proposta inovadora de ensino-aprendizagem. Ciênc Saúde Colet. 2012;17(3):787-96.

3. Lazzari DD, Martini JG, Busana JA. Teaching in higher education in nursing:an integrative literature review. Rev Gauch Enferm [Internet]. 2015 [cited 2016 Fev 23];36(3):93-101. Available from: http:/ / seer.ufrgs.br/ index.php/RevistaGauchadeEnfermagem/article/ view/49670/35065

4. Rodrigues CCFM, Carvalho DPSRP, Salvador PTCO, Medeiros SM, Menezes RMP, Ferreira Júnior MA, et al. Innovative nursing education from the perspective of epistemologies of the South. Esc Anna Nery Rev Enferm [Internet]. 2016 [cited 2016 Jun 10]; 20(2):3849. Available from: http://www.scielo.br/pdf/ean/ v20n2/en_1414-8145-ean-20-02-0384.pdf

5. Carvalho ACO, Soares JR, Maia ER, Machado MFAS, Lopes MSV, Sampaio KJAJ. Teacher planning: report on methods of assets used in nursing education. J Nurs UFPE on line [Internet]. 2016 [cited 2016 Jun 10]; 10(4):1332-8. Available from: http://www.revista. ufpe.br/revistaenfermagem/index.php/revista/ article/view/7685/pdf_10004

6. Formiga LMF, Gomes LCP, Oliveira EAR, Duailibe FT, Sousa LSN, Lima LHO. Atuação dos profissionais de enfermagem no serviço de emergência: um estudo descritivo. Rev Enferm UFPI [Internet]. 2014 [cited 2016 Jun 10]; 3(1):53-8. Available from: http:/ /www. ojs.ufpi.br/index.php/reufpi/article/view/1429/ pdf_1

7. Zandomenighi RC, Mouro DL, Oliveira CA, Martins EAP. Cuidados intensivos em um serviço hospitalar de emergência: desafios para os enfermeiros. REME rev. min. enferm. 2014;18(2):404-14.

8. Bulman C, Lathlean J, Gobbi M. The concept of reflection in nursing: qualitative findings on student and teacher perspectives. Nurse Educ Today [Internet]. 2012 [cited 2015 Nov 24];32(5):8-13. Available from: http:/ / ac.els-cdn.com/S0260691711002693/1-s2.0S0260691711002693-main.pdf?_tid=0ce484ee-4f6411e6-90be-00000aab0f27\&acdnat $=1469120361$ _ c156fad19e10b9426d7c28c9f8d75d32

9. Allan H, Smith P. Are pedagogies used in nurse education research evident in practice? Nurse Educ Today [Internet]. 2010 [cited 2015 Nov 24]; 30:476-9. Available from: http:/ / ac.els-cdn.com/ S0260691709002019/1-s2.0-S0260691709002019-main. pdf?_tid=65364722-4f64-11e6-ba83-00000aab0f27\&ac dnat=1469120509_3dec2539438ade64ef132f26f028e14a

10. Bardin, L. Análise de conteúdo. Lisboa (PT): edições 70, 2011.

11. Oliveira LB, Díaz LJR, Carbogim FC, Rodrigues ARB, Püschel VAA. Effectiveness of teaching strategies on the development of critical thinking in undergraduate nursing students: a meta-analysis. Rev Esc Enferm USP [Internet]. 2016 [cited 2016 Jun 21]; 50(2):350-9. Available from: http:/ / www.scielo.br/pdf/reeusp/ 
v50n2/0080-6234-reeusp-50-02-0355.pdf

12. Chicharo SCR, Florêncio MV, Alves SZSP, Cortez EA, Andrade M, Valente GSC. Factors facilitating the teaching-learning in nursing education: an integrative review. Rev Pesqui Cuid Fundam (Online) [Internet]. 2016 [cited 2016 Jun 10]; 8(2):4099-108. Available from: http://www.seer.unirio.br/index.php/ cuidadofundamental/article/view/3408/pdf_1841

13. Draganoc PB, Sanna MC. Assessment of nursing teachers abilities to facilitate adult learning. Cogitare Enferm. 2015;20(3):554-61.

14. Ramos SM, Barlem JGT, Lunardi VL, Barlem ELD, Silveira RS, Bordignon SS. Satisfaction with academic experience among undergraduate nursing students. Texto Contexto Enferm [Internet]. 2015 [cited 2017 Mar 27]; 24(1):187-95. Available from: http:/ / dx.doi. org/10.1590/0104-07072015002870013

15. Prado ML, Medina-Moya JL, Martínez-Riera JR. La producción del conocimiento en educación en enfermería en España y Brasil: una revisión integrativa. Texto Contexto Enferm. 2011;20(3):607-15.

16. Avelino CCV, Borges FR, Inagaki CM, Nery MA, Goyatá SLT. Development of a course in the Virtual Learning Environment on the ICNP®. Acta Paul Enferm [Internet]. 2016 [cited 2016 Jun 21]; 29(1):6976. Available from: http:/ / www.scielo.br/pdf/ape/ v29n1/en_1982-0194-ape-29-01-0069.pdf

17. Cotta RMM, Costa GD, Mendonça ET. Portfólio reflexivo: uma proposta de ensino e aprendizagem orientada por competências. Ciênc Saude Coletiva. 2013;18(6):1847-56.

18. Sobral PHAF, Silva AMP, Santos VEP, Santos RAA, Santos ALS.Practice nursing in emergency services: systematic review. Rev Pesqui Cuid Fundam (Online) [Internet]. 2013 [cited 2016 Jun 10];5(4):396-07.
Available from: http://www.seer.unirio.br/index. php/cuidadofundamental/article/view/1655/ pdf_892

19. Rios IC, Schraiber LB. A relação professor-aluno em medicina - um estudo sobre o encontro pedagógico. Rev Bras Educ Méd. 2012; 36(3):308-16.

20. Meira MDD, Kurcgant P. Nursing education: training evaluation by graduates, employers and teachers. Rev Bras Enferm [Internet]. 2016 [cited 2016 Jun 21]; 69(1):10-5. Avalaible from: http://www.scielo.br/ pdf/reben/v69n1/en_0034-7167-reben-69-01-0016. pdf

21. Nguyen DN, Zierler B, Nguyen HQ. A survey of nursing faculty needs for training in use of new technologies for education and practice. J Nurs Educ [Internet]. 2011 [cited 2015 May 12]; 50(4):181-9. Available from:10.3928/01484834-20101130-06

22. Vásquez ET. Los retos de la reespecificación curricular en autonomía universitária: aporte de la metateoría curricular neosistémica. Invest Educ Enferm [Internet]. 2012 [cited 2015 Jan 21]; 30(1):108-23. Available from: http:/ / www.scielo.org.co/pdf/iee/v30n1/v30n1a13. pdf

23. Silva LAA, Soder RM, Schimdt SM, Noal HC, Arboit EL, Marco VR. Teacher archetypes: perceptions of nursing students. Texto Contexto Enferm [Internet]. 2016 [cited 2017 Mar 27]; 25(2):e0180014. Available from: http:/ / www.scielo.br/pdf/tce/v25n2/01040707-tce-25-02-0180014.pdf

24. González-Chordá VM, Maciá-Soler ML. Evaluation of the quality of the teaching-learning process in undergraduate courses in Nursing. Rev Latino-am Enfermagem [Internet]. 2015 [cited 2016 Jun 10]; 23(4):700-7. Available from: http://www.revistas. usp.br/rlae/article/view/105677/104397
Correspondência: Luiz Alves Morais Filho

Universidade Federal do Rio Grande do Norte, Centro de Ciências da Saúde,

Departamento de Enfermagem. Campus Universitário, BR $101 \mathrm{~S} / \mathrm{N}$

59072970 - Lagoa Nova, Natal, RN, Brasil.

E-mail: moraisfilho2004@hotmail.com
Recebido: 19 de agosto de 2016

Aprovado: 07 de maio de 2017

This is an Open Access article distributed under the terms of the Creative Commons (CC BY). 